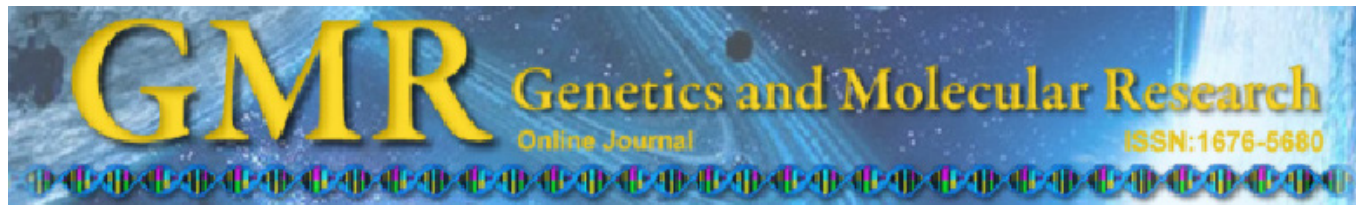

\title{
Meta-analysis demonstrates association between $T L R$ polymorphisms and rheumatoid arthritis
}

\author{
Y.H. Lee ${ }^{1}$, S.-C. Bae ${ }^{2}$ and G.G. Song ${ }^{1}$ \\ ${ }^{1}$ Division of Rheumatology, Department of Internal Medicine, \\ College of Medicine, Korea University, Seoul, Korea \\ ${ }^{2}$ Division of Rheumatology, Department of Internal Medicine, \\ Medical Center, Hanyang University, Seoul, Korea \\ Corresponding author: Y.H. Lee \\ E-mail: lyhcgh@korea.ac.kr
}

Genet. Mol. Res. 12 (1): 328-334 (2013)

Received March 7, 2012

Accepted August 3, 2012

Published February 7, 2013

DOI http://dx.doi.org/10.4238/2013.February.7.2

\begin{abstract}
We investigated whether Toll-like receptor (TLR) polymorphisms confer susceptibility to rheumatoid arthritis and whether they influence clinical characteristics of rheumatoid arthritis. Studies were considered relevant for our meta-analysis if at least two comparisons of an issue were available. Eleven studies with 2078 patients with rheumatoid arthritis and 2581 controls were included, encompassing European and Asian studies. Meta-analysis of three European studies showed no significant association between the TLR4 Asp299Gly (rs4986790) polymorphism and rheumatoid arthritis (odds ratio $=0.897,95 \%$ confidence interval $=0.734-1.096, \mathrm{P}=0.289$ ). One Turkish study showed a significant difference between TLR 9 rs 187084 allele frequencies and rheumatoid arthritis patients and controls, while another study revealed a significant association between rheumatoid factor and TLR8 rs5741883. A Korean study on the numbers of guanine-thymine $\left[(\mathrm{GT})_{\mathrm{n}}\right]$ repeats in intron II of the TLR2 gene found a significantly higher S-allele frequency in rheumatoid arthritis patients than in controls (30.3 vs 23.0\%). Overall findings for the meta-analysis
\end{abstract}


including all the studies conclude that TLR polymorphism is associated with development and clinical characteristics of rheumatoid arthritis in Asian and Middle East populations.

Key words: Toll-like receptor; Polymorphism; Rheumatoid arthritis

\section{INTRODUCTION}

Rheumatoid arthritis (RA) is a chronic inflammatory disease that affects predominantly synovial joints, causes significant morbidity, and shortens life expectancy. RA affects up to $1 \%$ of the world population. Although the etiology of RA is undetermined, a genetic component has been established, and human leukocyte antigen class II molecules are the most powerful genetic factors identified to date (Wordsworth and Bell, 1991). However, this association accounts for only one-third of the genetic susceptibility, and non-human leukocyte antigen genes are also known to be involved (Deighton et al., 1989).

Toll-like receptors (TLRs) constitute a family of transmembrane proteins expressed by various cell types, including immune cells, to identify pathogens and initiate inflammatory signaling pathways (Takeda et al., 2003). Stimulation of the TLR pathway culminates in nuclear factor $\mathrm{\kappa B}$ activation and the transcription of immune response genes (Drexler and Foxwell, 2010). To date, at least 10 human TLRs have been discovered; they recognize a variety of molecules, including lipoproteins, flagellin, and viral RNA or DNA (Roelofs et al., 2008). Furthermore, the administration of endogenous RNA or DNA has been shown to activate TLRs and induce autoimmune reactions (Hurst and von Landenberg, 2008). Based on the immune-regulating and immune-response-initiating effects of TLRs, they are considered candidate genes for RA.

Several studies have examined the potential contributions of $T L R$ polymorphisms to RA, but the results have been variable (Kilding et al., 2003; Radstake et al., 2004; Sanchez et al., 2004; Kuuliala et al., 2006; Lee et al., 2006; Kang and Lee, 2007; Sheedy et al., 2008; Jaen et al., 2009; Enevold et al., 2010; Zheng et al., 2010; Etem et al., 2011). In the present study, we used a systematic review approach to explore whether TLR polymorphisms confer susceptibility to RA or are related to its clinical characteristics.

\section{MATERIAL AND METHODS}

\section{Identification of eligible studies and data extraction}

A MEDLINE search was performed for studies published before October 2010 that examined associations between $T L R$ polymorphisms and RA with respect to susceptibility or disease severity. Combinations of key words such as Toll-like receptor, TLR, polymorphism, rheumatoid arthritis, and RA were entered as both medical subject headings and text words. References in identified studies were also examined to identify additional studies not indexed by MEDLINE. Studies on genetic or clinical associations that determined the distributions of $T L R$ alleles in RA patients or controls were eligible for inclusion in our systematic review. Meta-analysis was performed if at least 2 comparisons of an issue were available. 


\section{RESULTS}

\section{Studies included in the meta-analysis}

Eleven studies met the study inclusion criteria (Kilding et al., 2003; Radstake et al., 2004; Sanchez et al., 2004; Kuuliala et al., 2006; Lee et al., 2006; Kang and Lee, 2007; Sheedy et al., 2008; Jaen et al., 2009; Enevold et al., 2010; Zheng et al., 2010; Etem et al., 2011 (Table 1). These studies involved 2078 patients with RA and 2581 controls. Eight studies were casecontrol studies (Kilding et al., 2003; Radstake et al., 2004; Sanchez et al., 2004; Lee et al., 2006; Kang and Lee, 2007; Sheedy et al., 2008; Zheng et al., 2010; Etem et al., 2011), two were caseonly studies (Kuuliala et al., 2006; Enevold et al., 2010), and one was a family study (Jaen et al., 2009). Relevant features of the studies included in this systematic review are provided in Table 1.

\section{Association between $T L R$ polymorphisms and RA susceptibility and clinical findings}

Etem et al. (2011) found a significant difference between TLR9 rs187084 allele frequencies in Turkish RA patients and controls $(\mathrm{P}=0.003)$ but not between TLR3 rs3775290 and TLR10 rs4129009 polymorphisms. No associations were found between disease activity score 28 (DAS28) or autoantibodies and TLR3, 9, or 10 polymorphisms. Enevold et al. (2010) genotyped 22 polymorphisms in TLR2, 3, 4, 5, 7, 8, and 9 in 319 RA patients to investigate the relationship between these TLR polymorphisms and disease phenotype and RA severity. A moderate association was found between RF positivity and TLR8 rs5741883 $(\mathrm{P}=0.001)$, but no other TLR polymorphism was found to be associated with the clinical characteristics of RA. Lee et al. (2006) counted numbers of guanine-thymine repeats in intron II of the TLR2 gene in 183 Korean RA patients and 148 controls. In this study, alleles were classified as 12-16 GT repeats (S allele) and 17-28 repeats (L allele), and the results revealed that the $\mathrm{S}$ allele had a frequency in RA patients that was significantly higher than that in controls (30.3 vs $23.0 \%, \mathrm{P}=0.03)$.

\section{Meta-analysis of the TLR4 Asp299Gly (rs4986790) polymorphism and RA}

Six studies (4 European and 2 Asian studies), including 5 case-control studies (Kilding et al., 2003; Radstake et al., 2004; Kang and Lee, 2007; Sheedy et al., 2008; Zheng et al., 2010) and 1 case-only study (Kuuliala et al., 2006), addressed the TLR4 Asp299Gly (rs4986790) polymorphism. Both TLR4 Asp299Gly (rs4986790) and Thr399Ile (rs4986791) were investigated in the 2 Asian studies (1 Korean and 1 Chinese), but these polymorphisms were not detected (Kang and Lee, 2007; Zheng et al., 2010).

Owing to the limited number of studies on polymorphisms, meta-analysis was performed only on the TLR4 Asp299Gly (rs4986790) polymorphism. Three studies examined the association between this polymorphism and RA, and all were conducted in Europe (Kilding et al., 2003; Radstake et al., 2004; Sheedy et al., 2008). One study identified a difference in genotype frequency between patients and controls $(\mathrm{P}=0.025)$ (Radstake et al., 2004), but the other 2 found no significant association between this polymorphism and RA (Kilding et al., 2003; Sheedy et al., 2008). Furthermore, we also failed to find an association between this polymorphism and RA in Europeans through meta-analysis (odds ratio $=0.897,95 \%$ confidence interval $=0.734-1.096, \mathrm{P}=0.289$; Figure 1 ). In terms of clinical findings, the 3 European studies included in the meta-analysis found no association between this polymorphism and clinical characteristics. 
TLR polymorphisms and rheumatoid arthritis

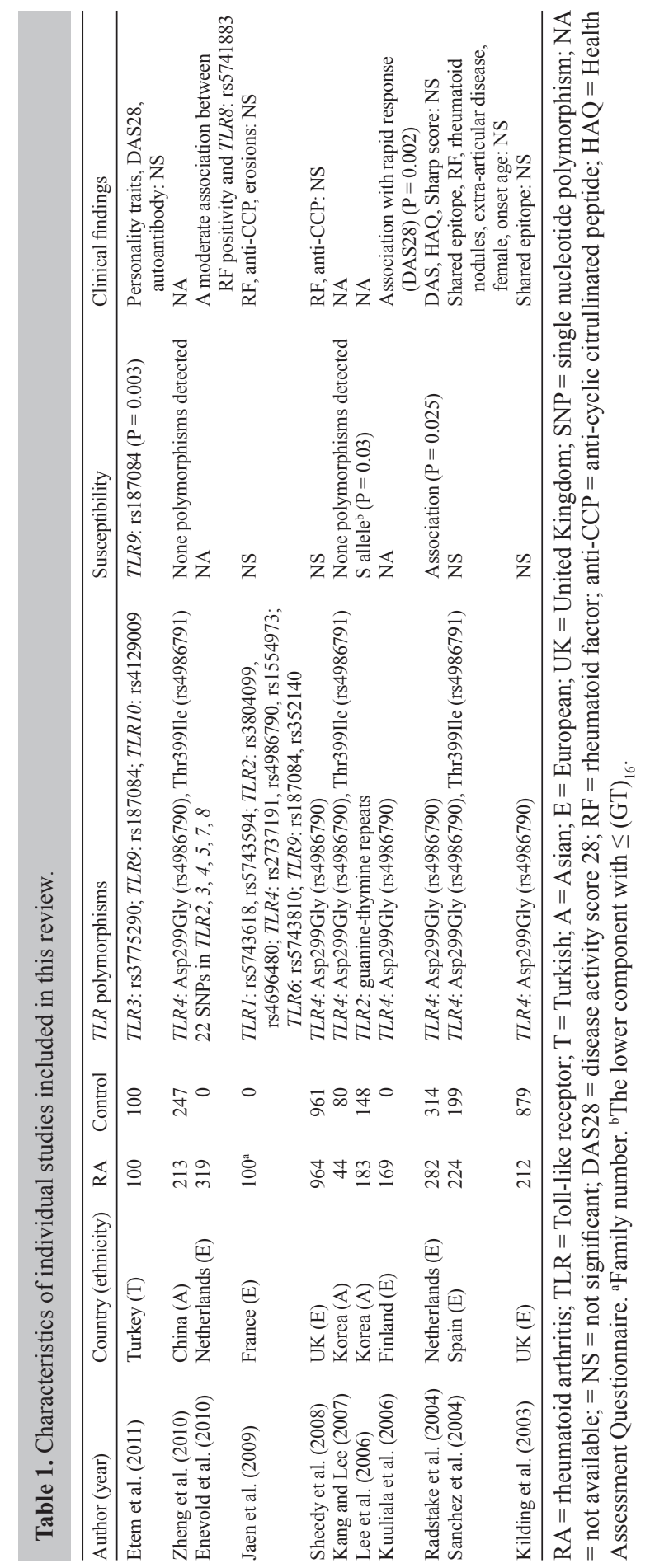

Genetics and Molecular Research 12 (1): 328-334 (2013) 


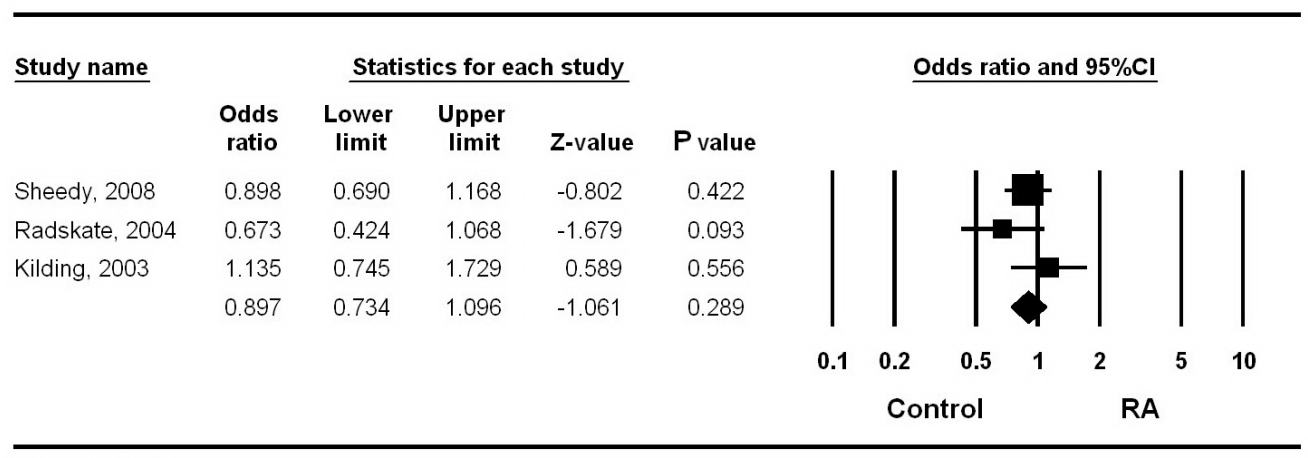

Meta analysis

Figure 1. Odds ratio and $95 \%$ confidence interval $(95 \% \mathrm{CI})$ of individual studies and pooled data for the 2 vs 1 TLR 4 Asp299Gly (rs4986790) polymorphism allele comparison with respect to rheumatoid arthritis (RA) susceptibility in Europeans.

The aim of the case-only study, which was performed with 169 RA patients by Kuuliala et al. (2006), was to determine whether the TLR4 Asp299Gly (rs4986790) polymorphism influences treatment response. The authors found that DAS28 was significantly different in RA patients with and those without this polymorphism who were treated with a disease-modifying anti-rheumatic drug $(\mathrm{P}=0.019)$ but not between RA patients with and those without this polymorphism treated with 3 disease-modifying anti-rheumatic drugs and prednisolone $(\mathrm{P}=0.31)$.

\section{DISCUSSION}

Viruses and bacteria are known to increase RA susceptibility and exacerbate RA by binding to TLRs (Drexler and Foxwell, 2010). Furthermore, TLRs have been suggested to play a role in responses to pathogens in RA based on findings obtained in animal models of arthritis in which bacterial cell wall components were used to induce experimental arthritis (Cromartie et al., 1977). In addition, TLR2, 3, 4, 7, and 9 are expressed in human RA synovial tissues (Radstake et al., 2004). Given the known genetic predisposition displayed in RA patients (Choi et al., 2006; Moon et al., 2010), TLR polymorphism studies have been conducted to determine whether TLR is involved in the pathogenesis of RA.

In the present study, we undertook a systematic review and meta-analysis of associations between TLR polymorphisms and RA in terms of disease susceptibility and severity. Some polymorphisms have been shown to be associated with susceptibility and clinical findings, but only 1 study has been conducted to date on each of these associations. For example, a significant difference in TLR9 rs 187084 allele frequencies was found between Turkish RA patients and controls. Etem et al. (2011) found a moderate association between rheumatoid factor and TLR8 rs5741883, and an increased S allele frequency in RA patients. However, no confirmatory study has been conducted to date.

The TLR4 Asp299Gly (rs4986790) polymorphism is the most frequently studied polymorphism in RA, and it displays ethnic differences. Africans have the highest frequency (16\%) (Mockenhaupt et al., 2006), followed by Europeans (4-10\%) (Adam et al., 2006), whereas Asians do not have this polymorphism (Zheng et al., 2010). In the present study, 
meta-analysis of the TLR4 Asp299Gly polymorphism failed to reveal any association with RA susceptibility in Europeans. The single case-only study found that DAS28 differed significantly in RA patients according to the presence of this polymorphism (Kuuliala et al., 2006), but the 3 case-control studies failed to identify an association between this polymorphism and the clinical characteristics of RA (Kilding et al., 2003; Radstake et al., 2004; Sheedy et al., 2008).

The present study has some limitations. First, the number of studies included in the systematic review might have been too small to detect slight associations within ethnic groups. Second, our meta-analysis included data from European patients, and thus, our results are applicable only to this ethnic group. Furthermore, only 3 studies were conducted in Europeans (Kilding et al., 2003; Radstake et al., 2004; Sheedy et al., 2008), which may mean that our investigation was underpowered (Sung et al., 2009; Wang et al., 2010).

Although we found no major contribution of TLR polymorphisms to RA, our results suggest that the TLR polymorphism is associated with the development and clinical characteristics of RA. However, because only a relatively small number of studies have investigated the roles of TLR polymorphisms in the pathogenesis of RA, further research is required to determine whether the polymorphisms of TLR contribute to RA susceptibility and severity.

\section{ACKNOWLEDGMENTS}

Research supported by a grant from the Korea Healthcare Technology R\&D Project, Ministry of Health and Welfare, Republic of Korea (\#A102065).

\section{Conflict of interest statement}

We have no financial conflicts of interest.

\section{REFERENCES}

Adam R, Sturrock RD and Gracie JA (2006). TLR4 mutations (Asp299Gly and Thr399Ile) are not associated with ankylosing spondylitis. Ann. Rheum. Dis. 65: 1099-1101.

Choi SJ, Rho YH, Ji JD, Song GG, et al. (2006). Genome scan meta-analysis of rheumatoid arthritis. Rheumatology 45: $166-170$.

Cromartie WJ, Craddock JG, Schwab JH, Anderle SK, et al. (1977). Arthritis in rats after systemic injection of streptococcal cells or cell walls. J. Exp. Med. 146: 1585-1602.

Deighton CM, Walker DJ, Griffiths ID and Roberts DF (1989). The contribution of HLA to rheumatoid arthritis. Clin. Genet. 36: 178-182.

Drexler SK and Foxwell BM (2010). The role of toll-like receptors in chronic inflammation. Int. J. Biochem. Cell Biol. 42: 506-518.

Enevold C, Radstake TR, Coenen MJ, Fransen J, et al. (2010). Multiplex screening of 22 single-nucleotide polymorphisms in 7 Toll-like receptors: an association study in rheumatoid arthritis. J. Rheumatol. 37: 905-910.

Etem EO, Elyas H, Ozgocmen S, Yildirim A, et al. (2011). The investigation of toll-like receptor 3, 9 and 10 gene polymorphisms in Turkish rheumatoid arthritis patients. Rheumatol. Int. 31: 1369-1374.

Hurst J and von Landenberg P (2008). Toll-like receptors and autoimmunity. Autoimmun. Rev. 7: 204-208.

Jaen O, Petit-Teixeira E, Kirsten H, Ahnert P, et al. (2009). No evidence of major effects in several Toll-like receptor gene polymorphisms in rheumatoid arthritis. Arthritis Res. Ther. 11: R5.

Kang ES and Lee J (2007). Genotypic analysis of Asp299Gly and Thr399Ile polymorphism of Toll-like receptor 4 in systemic autoimmune diseases of Korean population. Rheumatol. Int. 27: 887-889.

Kilding R, Akil M, Till S, Amos R, et al. (2003). A biologically important single nucleotide polymorphism within the tolllike receptor-4 gene is not associated with rheumatoid arthritis. Clin. Exp. Rheumatol. 21: 340-342. 
Kuuliala K, Orpana A, Leirisalo-Repo M, Kautiainen H, et al. (2006). Polymorphism at position +896 of the toll-like receptor 4 gene interferes with rapid response to treatment in rheumatoid arthritis. Ann. Rheum. Dis. 65: 1241-1243.

Lee EY, Yim JJ, Lee HS, Lee YJ, et al. (2006). Dinucleotide repeat polymorphism in intron II of human Toll-like receptor 2 gene and susceptibility to rheumatoid arthritis. Int. J. Immunogenet. 33: 211-215.

Mockenhaupt FP, Cramer JP, Hamann L, Stegemann MS, et al. (2006). Toll-like receptor (TLR) polymorphisms in African children: Common TLR-4 variants predispose to severe malaria. Proc. Natl. Acad. Sci. U. S. A. 103: 177-182.

Moon SJ, Park MK, Oh HJ, Lee SY, et al. (2010). Engagement of toll-like receptor 3 induces vascular endothelial growth factor and interleukin-8 in human rheumatoid synovial fibroblasts. Korean J. Intern. Med. 25: 429-435.

Radstake TR, Franke B, Hanssen S, Netea MG, et al. (2004). The Toll-like receptor 4 Asp299Gly functional variant is associated with decreased rheumatoid arthritis disease susceptibility but does not influence disease severity and/or outcome. Arthritis Rheum. 50: 999-1001.

Roelofs MF, Abdollahi-Roodsaz S, Joosten LA, van den Berg WB, et al. (2008). The orchestra of Toll-like receptors and their potential role in frequently occurring rheumatic conditions. Arthritis Rheum. 58: 338-348.

Sanchez E, Orozco G, Lopez-Nevot MA, Jimenez-Alonso J, et al. (2004). Polymorphisms of toll-like receptor 2 and 4 genes in rheumatoid arthritis and systemic lupus erythematosus. Tissue Antigens 63: 54-57.

Sheedy FJ, Marinou I, O'Neill LA and Wilson AG (2008). The Mal/TIRAP S180L and TLR4 G299D polymorphisms are not associated with susceptibility to, or severity of, rheumatoid arthritis. Ann. Rheum. Dis. 67: 1328-1331.

Sung IH, Kim TH, Bang SY, Kim TJ, et al. (2009). IL-23R polymorphisms in patients with ankylosing spondylitis in Korea. J. Rheumatol. 36: 1003-1005.

Takeda K, Kaisho T and Akira S (2003). Toll-like receptors. Annu. Rev. Immunol. 21: 335-376.

Wang X, Huang J, Lin Z, Liao Z, et al. (2010). Single-nucleotide polymorphisms and expression of IL23R in Chinese ankylosing spondylitis patients. Rheumatol. Int. 30: 955-959.

Wordsworth P and Bell J (1991). Polygenic susceptibility in rheumatoid arthritis. Ann. Rheum. Dis. 50: 343-346.

Zheng B, Li Q, Wei C, Qin J, et al. (2010). Lack of association of TLR4 gene Asp299Gly and Thr399Ile polymorphisms with rheumatoid arthritis in Chinese Han population of Yunnan Province. Rheumatol. Int. 30: 1249-1252. 